\title{
INCEFA-PLUS PROJECT: REVIEW OF THE TEST PROGRAMME AND MAIN RESULTS
}

\author{
Gintautas DUNDULIS ${ }^{1}$, Albertas GRYBENAS ${ }^{1}$, Matthias BRUCHHAUSEN ${ }^{2}$, Roman CICERO $^{3}$, \\ Kevin MOTTERSHEAD ${ }^{4}$, Caitlin HUOTILAINEN ${ }^{5}$, Jean-Christophe LE ROUX ${ }^{6}$, \\ Marc VANKEERBERGHEN ${ }^{7}$ \\ 1'Lithuanian Energy Institute, 44403 Kaunas, Lithuania, Gintautas.Dundulis@lei.It \\ 2European Commission, Joint Research Centre (JRC), 1755 LE Petten, The Netherlands \\ 3 Inesco Ingenieros, 39005 Santander Spain \\ ${ }^{4}$ Wood - Europe, Warrington, Cheshire WA3 6GA United Kingdom \\ ${ }^{5}$ VTT Technical Research Centre of Finland Ltd., Espoo, 02044 Finland \\ ${ }^{6} E D F$ - Recherche et Développement, 77818 Moret Sur Loing Cedex, France \\ ${ }^{7}$ SCK·CEN - Nuclear Materials Science Institute, 2400 Mol, Belgium
}

https://doi.org/10.37904/metal.2020.3496

\begin{abstract}
INCEFA-PLUS (INcreasing Safety in NPPs by Covering gaps in Environmental Fatigue Assessment) project characterized environmentally assisted fatigue of stainless steels in light water reactor environments. During this project more than 200 fatigue tests have been carried out in different laboratories across Europe in air and water environment. Most tests were performed on a single batch of $304 \mathrm{~L}$, an austenitic stainless steel alloys employed in NPPs. The tests addressed the effects of strain amplitude, hold time periods, material roughness and mean strain/stress on fatigue endurance. A limited number of tests was carried out on other batches of 304L and on X6 CrNiTi 18 10, a Ti stabilised steel used in VVERs. Additionally, activities on the effects of mean stress under strain control, testing at reduced environmental fatigue correction factor $F_{\text {en, }}$ and different applications of hold time as well as biaxial fatigue tests have been carried out. The data obtained has been collected and standardised in an online environmental fatigue database MatDB.
\end{abstract}

Keywords: Experimental testing fatigue, environment fatigue, steel 304L

\section{INTRODUCTION}

INCEFA-PLUS (INcreasing Safety in NPPs by Covering gaps in Environmental Fatigue Assessment) is a project supported by the European Commission HORIZON2020 programme. 16 organisations from across Europe are participating in this project. During this project, new experimental data was obtained which will support the development of improved guidelines for assessment of environmental fatigue damage to ensure safe operation of nuclear power plants.

The objective of the INCEFA-PLUS project was to develop new guidelines for the assessment of environmental fatigue damage susceptibility for NPP components. Accordingly, in this project has been invested to improve understanding of EAF in LWR conditions, e.g. [1,2,3]. The INCEFA-PLUS project was started to study the influences of the parameters strain range $\Delta \varepsilon$, mean strain $\varepsilon$, surface roughness $R_{t}$, hold time th and environment on the fatigue life $\mathrm{N}_{\mathrm{f}}$ of stainless steels of relevance for European LWRs. For the INCEFA-PLUS the summary of test conditions and relevant parameter ranges is presented in Table 1.

This paper summarizes the data that is generated during the project and provides a preliminary overview of the hold effects to fatigue. 
Table 1 Summary of the test conditions ( $\dot{\varepsilon}$-strain rate, $T$ - temperature) [4]

\begin{tabular}{|c|c|c|c|c|}
\hline Parameter & Low level & Middle level & High level & Comment \\
\hline$\Delta \varepsilon[\%]$ & 0.6 & & 1.2 & \\
\hline$\varepsilon[\%]$ & 0 & & 0.5 & only for phase I \\
\hline $\mathrm{R}_{\mathrm{t}}[\mu \mathrm{m}]$ & 0.76 & $\approx 20$ & $>40$ & Rt $>40$ for phase II only \\
\hline $\operatorname{th}[\mathrm{h}]$ & 0 & & 72 & $\begin{array}{l}0 \text { or } 3 \text { holds of } 72 \mathrm{~h} \text { at mean strain; cycles with } \\
\text { holds depend on test conditions, see Table } 2\end{array}$ \\
\hline$\dot{\varepsilon}[\% / s]$ & 0.01 & & 0.1 & $\begin{array}{l}\text { rising } \dot{\varepsilon} \text { in PWR env., falling } \dot{\varepsilon} \text { and air tests may } \\
\text { vary; }{ }^{\prime} \varepsilon=0.1 \% / \mathrm{s} \text { in phase III only }\end{array}$ \\
\hline $\mathrm{T}\left[{ }^{\circ} \mathrm{C}\right]$ & 230 & & 300 & $\mathrm{~T}=230^{\circ} \mathrm{C}$ in phase III only \\
\hline
\end{tabular}

\section{TEST PROGRAMME}

The INCEFA-PLUS test programme has been divided in three phases. During first two years tests for phase I were performed, in the third year - phase II, and after that - Phase III. Dividing the programme in different phases allowed slightly reorienting the later phases when the data from earlier phases became available. The programme focussed on the effects of the parameters strain rate $\Delta \varepsilon$, mean strain $\varepsilon$, surface roughness $R_{t}$, hold time $t_{h}$ and environment as well as their interactions on the fatigue life $\mathrm{N}_{\mathrm{f}}$ in strain controlled LCF tests. The three test phases had slightly different foci:

I. During the first test phase two values of each of parameters were considered. It was analysed strain rate $\Delta \varepsilon$, mean strain $\varepsilon$, surface roughness $R_{t}$, hold time th and environment on fatigue life $\mathrm{N}_{\mathrm{f}}$.

II. Because during phase I was not detected of an effect of mean strain $\varepsilon$ on fatigue life $\mathrm{N}_{\mathrm{f}}$ this parameter was dropped from the main test programme in phase II and a third surface roughness was introduced. In parallel, a limited test programme on the effects of mean stress under strain and stress control was carried out.

III. The programme on strain and stress controlled testing with mean stress started in phase II was extended in phase III.

Some additional effects also needed to be considered:

- $\quad$ Specimen type: While all air tests and most tests in LWR environment were carried on full cylindrical specimens, some of the tests in environment were performed using hollow specimens. The final surface preparation processes varied depending on the type of specimen and desired surface roughness: polishing and grinding for full specimens and honing for hollow specimens

- Material: Most tests were carried out on a single batch of $304 \mathrm{~L}$ austenitic steel. But some data contributed from national programmes are on different heats of 304L, 316, or X6 CrNiTi 1810 , a Ti stabilized austenitic stainless steel used in VVERs.

- Laboratory: The tests were carried out in different laboratories across Europe. To reduce interlaboratory scatter as far as possible, a detailed test protocol was defined to harmonize the test procedures for the project.

Each test record is uploaded to a materials database operated by the European Commission (https://odin.jrc.ec.europa.eu/) and can be accessed by all project partners. Once a dataset is validated by the testing organization, a report is generated from the data stored in the database. A panel of fatigue experts from within the consortium considers every test on the basis of data like the cyclic stress and hysteresis curves. Only data that has been approved by the expert panel can be used in the final evaluation. 


\section{TEST RESULTS}

The test data has been uploaded to the data base and validated by the expert panel. The data used for the present study consists of 128 fatigue tests on the common material, batch XY182 sheet 23201 of 304L produced by Creusot Loire Industries. The data used here [5] contain:

- $\quad 53$ tests in air and 75 in PWR conditions. 114 tests on full specimens and 14 tests on hollow specimens.

- 62 ground and 52 polished solid specimens; the hollow specimens all had a honed surface finish. 3 runouts; these are indicated by $\triangleright$ in the plots.

The fatigue life $\mathrm{N}_{f}$ for the solid specimens is characterized as $\mathrm{N}_{25}$ i.e. the cycle during which the maximum stress during a cycle drops by $25 \%$ compared to the extrapolation of the quasi-linear part of the maximum cyclic stress vs. cycle curve.

The testing results in air and PWR condition at different strain range and compared to the mean reference curves from CR 6909 in air and PWR water is presented in Figure 1.

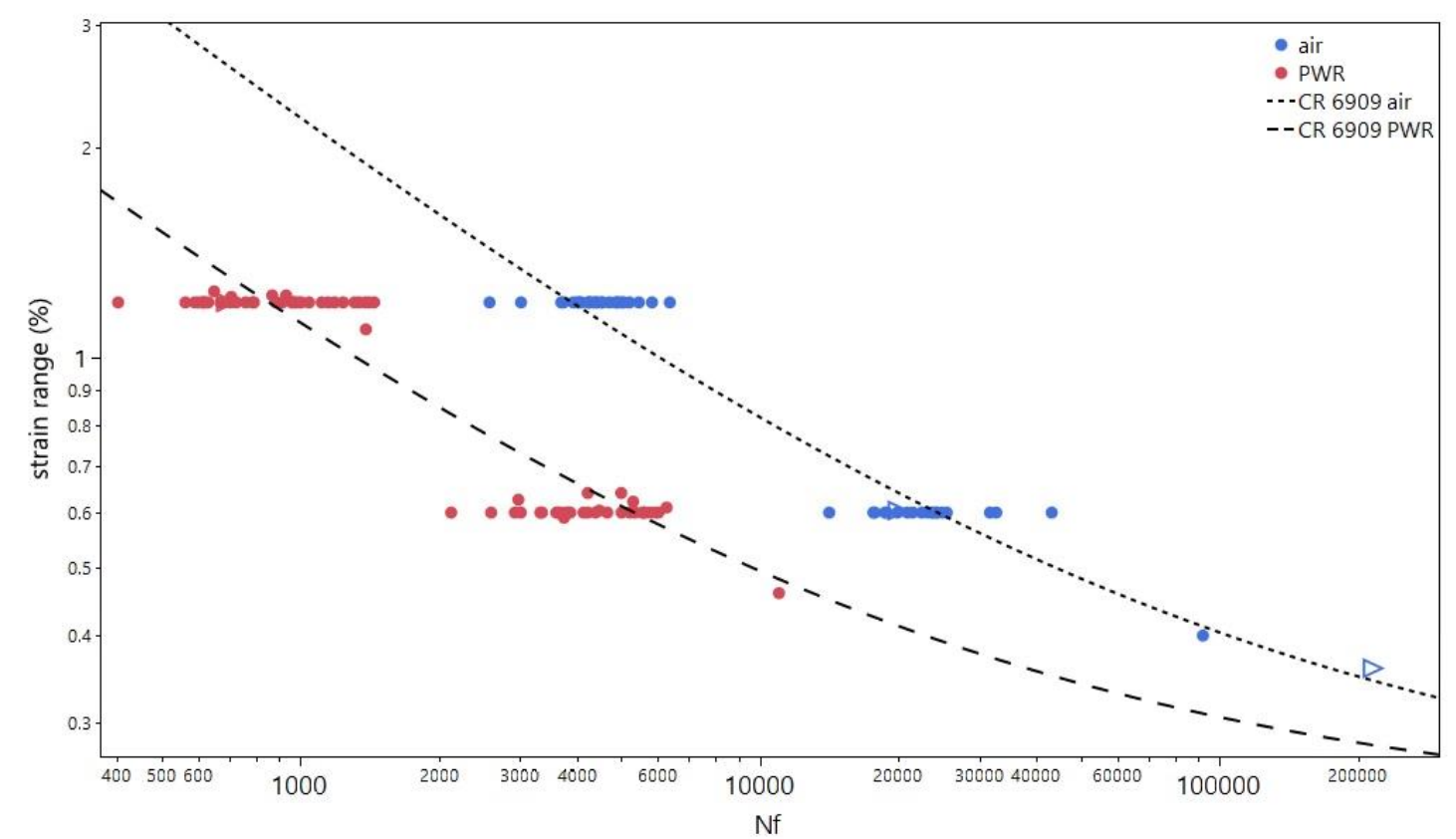

Figure 1 Plot of the test data [5]. The NUREG CR-6909 mean curves for air (red) and PWR water (blue)

\section{HOLD EFFECTS TO FATIGUE}

VTT and E.ON have primarily tested Type 347 stabilised austenitic stainless steel in air using multiple hold times at elevated temperature of between 4 hours and 48 hours, with either a constant stress or constant strain maintained during each hold. Holds were applied between periods of strain controlled cyclic loading (in air) at either room temperature or elevated temperature [6]. A smaller number of results for Type 304 unstabilised material have also been reported. However, these tests with shorter holds were carried out at higher strain amplitudes $(0.6 \%, 0.4 \%)$ at which the effects of longer holds may also be insignificant. In INCEFA+ hold time parameters for Phase I and II testing in strain-control are presented in Table 1 and Table 2. Hold position was during positive strain rate and hold strain at mean strain during cycle ( $0 \%$ or $0.5 \%)$. During fatigue a positive strain rate is $0.01 \% / \mathrm{s}$ and negative strain rate $-0.1 \% / \mathrm{s}$. Loading waveforms and hysteresis loops in air environment at $300{ }^{\circ} \mathrm{C}$ and hold period $(72 \mathrm{~h})$ at $\varepsilon=0 \%$ is presented in Figure $\mathbf{2} \mathbf{a}, \mathbf{b}$. The hysteresis loops (c) in air environment at $300{ }^{\circ} \mathrm{C}$ and hold period (72 hours) at $\varepsilon=0 \%$ is presented in Figure 2c. 
Table 2 Hold periods frequency

\begin{tabular}{|c|c|c|}
\hline \multirow{2}{*}{$\varepsilon_{a}(\%)$} & Air environment $\left(\mathbf{3 0 0}{ }^{\circ} \mathbf{C}\right)$ & LWR environment $\left(\mathbf{3 0 0}{ }^{\circ} \mathbf{C}\right)$ \\
\cline { 2 - 3 } & Number cycles of the start a 3 holds & Number cycles of the start a 3 holds \\
\hline 0.3 & 6000,12000 and 18000 & 1200,2400 and 3600 \\
\hline 0.6 & 1000,2000 and 3000 & 200,400 and 600 \\
\hline
\end{tabular}

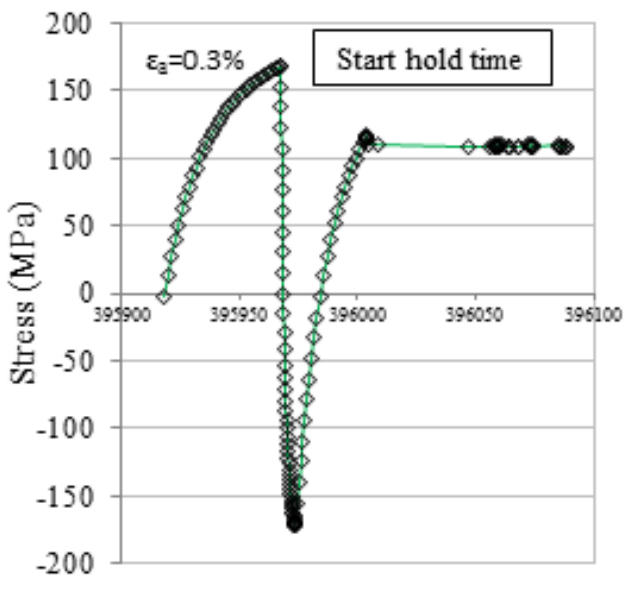

Time (s)

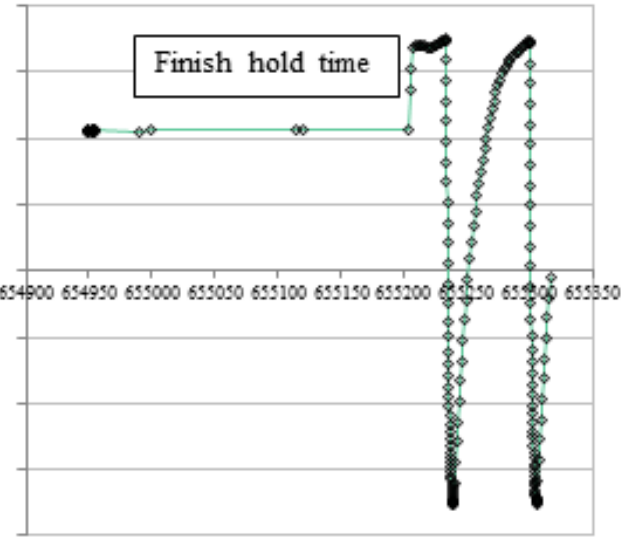

Time (s)

a)

b)

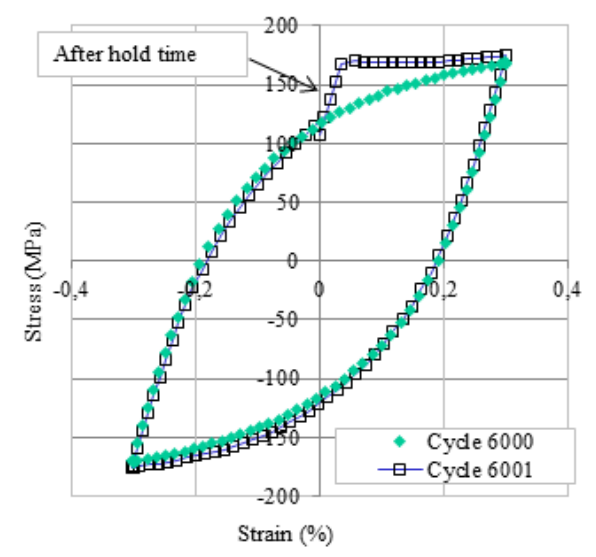

C)

Figure 2 Loading waveforms ( $a$-at start of hold, $b$ - at finish of hold, scaling of the stress axis is same) and hysteresis loops (c) in air environment at $300{ }^{\circ} \mathrm{C}$ and hold period (72 hours) at $\varepsilon=0 \%$

As can see from Figure 3 the general trend of stress changes from number of fatigue is similar with and without holds. Only immediately after holding the stress increases, but after some time becomes same as stress without hold during fatigue. The results from phases I and II did not show any hold time effect - in contrast to what was observed elsewhere. Likely reasons for this discrepancy are differences between the applications of the hold time during the fatigue cycle. To increase the probability of observing a hold time effect, the strain range was reduced to $0.4 \%$ and holds were performed under zero load control in Phase III. The hold times consist of three off 72 hours holds at $350^{\circ} \mathrm{C}$ at 10.000 cycle intervals starting from the 10.000 th cycles. Two of the tests feature cycling at an elevated temperature and two others cycling at room temperature. The latter case has been included since it should provide a more definitive answer for the effect of holds on 304L material with respect to hold time experiments conducted in the literature. 


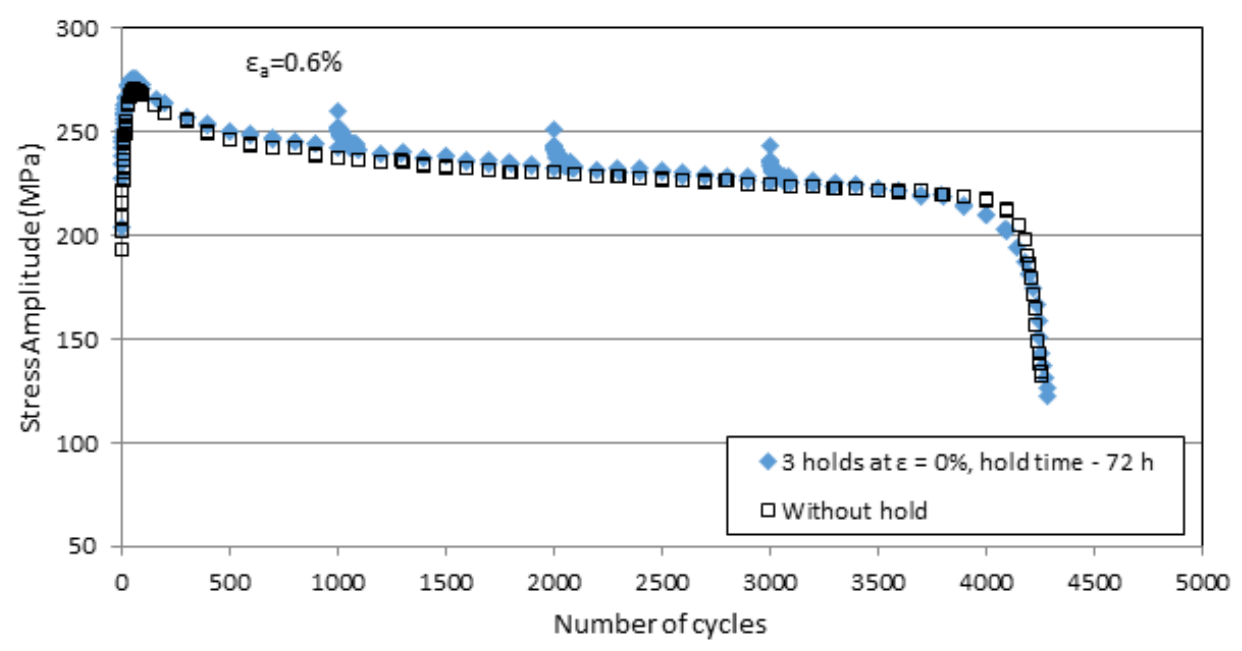

Figure 3 Stress amplitude versus cycles: comparison between LCF tests in air environment at $300^{\circ} \mathrm{C}$ with and without hold periods

At present time Phase III testing on hold effect is continuing according a described condition. The first testing data on hold effect are presented in Figure 4. The presented results at room temperature after each hold occurs hardening of the steel 304 . After each hold the stress decreases, but the level of stresses are higher than before hold. In addition, the level of stresses is higher than in the case fatigue without hold.

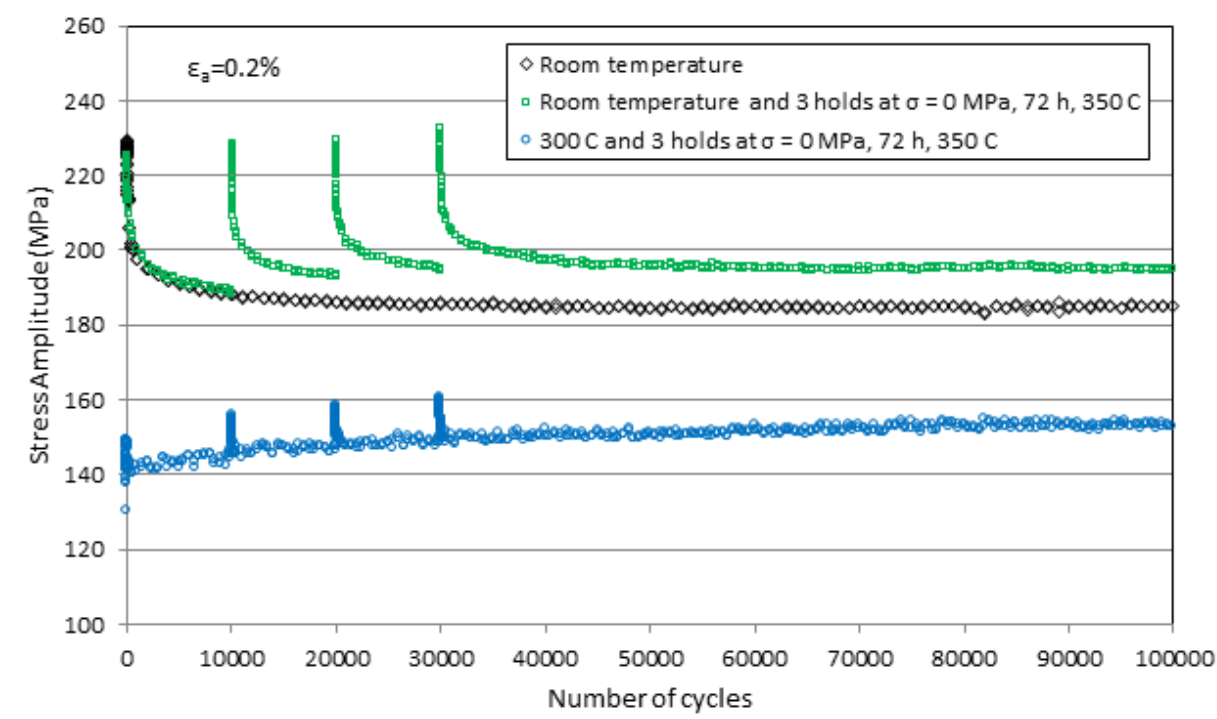

Figure 4 Effect of temperature and hold periods on cyclic stress amplitude of $304 \mathrm{~L}$ steel in air environment

Given that some codes and standards have made provision for a future hold time effect, it is important that the INCEFA+ programme develops a robust and defensible position on hold times to disseminate to the international community.

\section{CONCLUSION}

The INCEFA-PLUS project has produced a large set of fatigue data in air as well as in a PWR environment. While testing and data upload for conditions with $F_{\text {en }}=2: 68$ is ongoing, the data with $F_{\text {en }}=4: 57$ is almost complete. In the current work, 128 fatigue tests on a single batch of $304 \mathrm{~L}$ austenitic steel have been presented. 
The fatigue life testing results in Phase I and Phase II did not show any hold time effect fatigue life $\mathrm{N}_{\mathrm{f}}$. The Phase III testing on hold effect is continuing and the conclusions will be reassessed once the complete data is available.

\section{ACKNOWLEDGEMENTS}

The authors gratefully acknowledge the INCEFAPLUS consortium for providing the data and the expert panel for the assessment of the individual data sets.

\section{This project has received funding from the Euratom Research and Training Programme 2014-2018 under Grant Agreement No. 662320.}

\section{REFERENCES}

[1] HERBST, M., ROTH, A., and RUDOLPH, J. Study on hold-time effects in environmental fatigue lifetime of lowalloy steel and austenitic stainless steel in air and under simulated PWR primary water conditions, In Proceedings of the 18th International Conference on Environmental Degradation of Materials in Nuclear Power Systems Water Reactors, J. H. Jackson, D. Paraventi, and M. Wright, eds., Springer International Publishing, 2018. pp. 987-1006.

[2] HARRISON, H., and GURDAL, R. Comparison between ASME code case N-761, NUREG/CR-6909 and stainless steel component fatigue test results. In Proceedings of the ASME 2014 Pressure Vessels \& Piping Conference, Vol. 1. PVP2014-28883, 2014, 14 pages, https://doi.org/10.1115/PVP2014-28883.

[3] METAIS, T., MORLEY, A., de BAGLION, L., TICE, D., STEVENS, G., and CUVILLIEZ, S. Explicit quantification of the interaction between the PWR environment and component surface finish in environmental fatigue evaluation methods for austenitic stainless steels. In Proceedings of the ASME 2018, Pressure Vessels and Piping Conference, Vol. 1A. PVP2018-84240, 2018, 10 pages, https://doi.org/10.1115/PVP2018-84240.

[4] BRUCHHAUSEN, M., MCLENNAN, A., CICERO R., HUOTILAINEN C., MOTTERSHEAD, K., ROUX, J-C., VANKEERBERGHEN M. INCEFA-PLUS project: Review of the test programme. In Proceedings of the ASME 2020 Pressure Vessels \& Piping Conference, Online, Virtual. PVP2020- 21377, 2020, 10 pages, (paper accepted).

[5] BRUCHHAUSEN, M. Collection of fatigue data from the INCEFA + project, version 1.0. European Commission JRC, v1.0, [catalog], 2020 (online). Available from: http://dx.doi.org/10.5290/50.

[6] SOLIN J., REESE S., KARABAKI H.E. AND MAYINGER W. Research on hold time effects in fatigue of stainless steel - simulation of normal operation between fatigue transients. In Proceedings of the ASME 2015 Pressure Vessels and Piping Conference, Vol. 1A. PVP2015-45098, 2015, 9 pages, https://doi.org/10.1115/PVP201545098. 